\title{
An Often-Overlooked Etiology of Pleuritic Chest Pain
}

\author{
Jacob E. Berchuck, $M D^{7}$ and Shalini Patel, $M D^{1,2}$ \\ 'Department of Medicine, University of California San Francisco, San Francisco, CA, USA; ${ }^{2}$ Department of Medicine, San Francisco Veterans Affairs \\ Medical Center, San Francisco, CA, USA.
}

KEY WORDS: Clinical image; Diagnosis; Cardiovascular disease; Pulmonary disease.

J Gen Intern Med 31(1):138

DOI: $10.1007 / \mathrm{s} 11606-015-3316-4$

(c) Society of General Internal Medicine 2015

A n 80-year-old man with history of coronary artery disease (CAD) and deep vein thrombosis (DVT) was admitted for left-sided pleuritic chest pain. Physical exam, ECG, $\mathrm{CBC}$, electrolytes, and troponin were unrevealing. Chest $\mathrm{CT}$ with contrast demonstrated a swirling soft tissue density in the anterior mediastinum, with prominent epipericardial fat stranding extending inward to the pericardial surface with inflammatory changes of the left posterior pericardium itself,

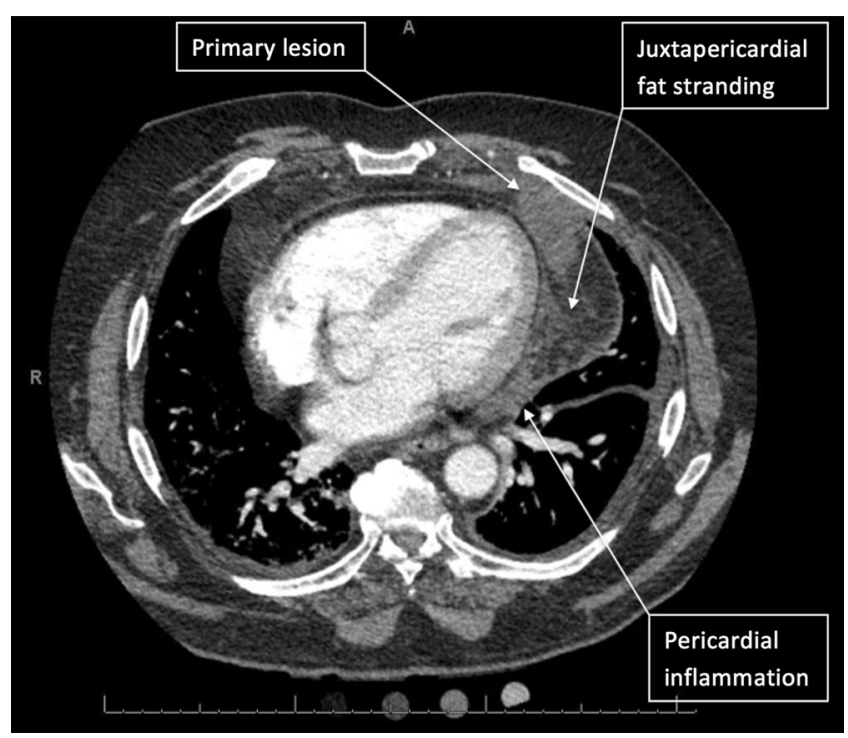

Fig. 1 The patient's chest $\mathrm{CT}$ showing characteristic radiographic findings of epipericardial fat necrosis consistent with epipericardial fat necrosis (EPFN). Ibuprofen was started, and at 3-month follow-up, chest pain had resolved and CT showed near complete resolution of the initial radiographic findings (Fig. 1).

EPFN is an often-overlooked etiology of pleuritic chest pain in patients with a negative cardiopulmonary workup. ${ }^{1}$ Onset is usually acute, but can persist up to a year. ECG and lab tests are usually normal. CXR often shows a paracardiac opacity, occasionally with an associated pleural effusion. CT shows an ovoid density in the juxtapericardial fat, with prominent stranding extending to the pericardial surface with inflammatory changes of the pericardium. ${ }^{2}$ The triad of pleuritic chest pain, classic CT findings, and negative cardiopulmonary work-up is highly suggestive of EPFN. ${ }^{3}$ Because of its selflimiting nature, the treatment is conservative management with NSAIDs. ${ }^{4}$ Follow-up imaging is recommended to confirm resolution and exclude neoplastic diseases such as liposarcoma.

Conflict of interest: The authors report no conflicts of interest related to the work described in this manuscript.

Corresponding Author: Jacob E. Berchuck, MD; Department of Medicine, University of California San Francisco, 505 Parnassus Avenue, Room M-987, San Francisco, CA 94143-0119, USA (e-mail:jacob.berchuck@ucsf.edu).

\section{REFERENCES}

1. Giassi Kde S, Costa AN, Bachion GH, et al. Epipericardial fat necrosis: an underdiagnosed condition. Br J Radiol. 2014;87:20140118.

2. Bhatt MY, Martínez-Jiménez S, Rosado-de-Christenson M, Watson $\mathbf{K}$, Walker CM, Kunin JR. Imaging manifestations of mediastinal fat necrosis. Case Rep Radiol. 2013;2013:323579.

3. Pineda V, Cáceres J, Andreu J, Vilar J, Domingo ML. Epipericardial fat necrosis: radiologic diagnosis and follow-up. Am J Roentgenol. 2005; 185:1234-6.

4. Jouan F, Sacre K, Debray MP, Crestani B, Chauveheid MP, Papo T. A 70year-old woman with acute chest pain and a paracardiac mass. Chest. 2013;143(3):866-9.

Presentations: An earlier version of this manuscript has been accepted and will be presented as a poster at the 2015 Society of General Internal Medicine Annual Meeting.

Received February 15, 2015

Accepted March 18, 2015

Published online April 14, 2015 